\title{
Phytophotodermatitis following the use of Ammi Majus Linn (Bishop's weed) for vitiligo
}

\author{
Imane Alouani' ${ }^{1}$, Nadia Fihmi', Nada Zizi ${ }^{1,2}$, Siham Dikhaye ${ }^{1,2}$
}

\begin{abstract}
${ }^{1}$ Department of Dermatology, Mohammed 6 University Hospital of Oujda - Medical School of Oujda, Mohammed First University of Oujda, Morocco, ${ }^{2}$ Laboratory of Epidemiology, Clinical Research and Public Health, Medical School of Oujda, Mohammed First University of Oujda, Morocco
\end{abstract}

Corresponding author: Dr. Imane Alouani, E-mail: alouani01@gmail.com

Sir,

Phytophotodermatitis (PPD) is a well-known entity that is causes by sequential exposure to certain species of plants and then to sunlight. In our social context where many patients resort to use herbal medicine, we report a case of a phytophotodermatitis following the use of Ammi majus L. as a treatment of vitiligo.

A 46 years old patient was presenting vitiligo since the age of 15 . After having a "prescription" from a radio show, she applied a mix of Ammi majus leaves, also known as Bishop's weed, and Anacyclus pyrethrum on her vitiligo skin lesions and then exposed herself directly to the sunlight. One day later, she developed a burning sensation, pain, itch and erythema on her vitiligo patches, she subsequently developed multiple bullae (Fig. 1). A diagnosis of phytophotodermatosis was made, with a complete resolution of her symptoms after symptomatic treatment.

Phyotophotodermatitis is a cutaneous phototoxic inflammatory eruption resulting from contact with light-sensitizing botanical substances and long-wave ultraviolet radiation [1]. Those substances usually contain furocoumarins. The intensity of the induced phototoxic reaction depends upon a number of factors. Many studies and case reports have described different plants with a different ability to cause a phototoxic reaction.

Amongst the family of the Apiaceae, the Ammi majus Linn, used by our patient, is well-known for its photo- toxic and photo-allergic properties [2]. Its content of coumarin is ranging from 50 to $900 \mathrm{mg}$ per $100 \mathrm{~g}$ [3]. It was responsible of a dermal-epidermal cleavage, leading to apparition of vesicles and bullae. Two other cases of phytophotodermatitis by using Ammi majus L. were reported in literature [1-4]. Other authors described cases of urticaria, allergic rhinitis and ocular toxicity after the use of this plant [5].

On the other hand, and since the $13^{\text {th }}$ century, the Egyptians have used a powder prepared from the fruit of this plant for the treatment of leukodermas. However, the powder of Ammi Majus Linn, just like that of Ammi Visnaga, provoked such undesirable manifestations as headache, nausea, vomiting, diarrhea, gastric burning and, when given in very strong doses, even nephritis and coma [6].

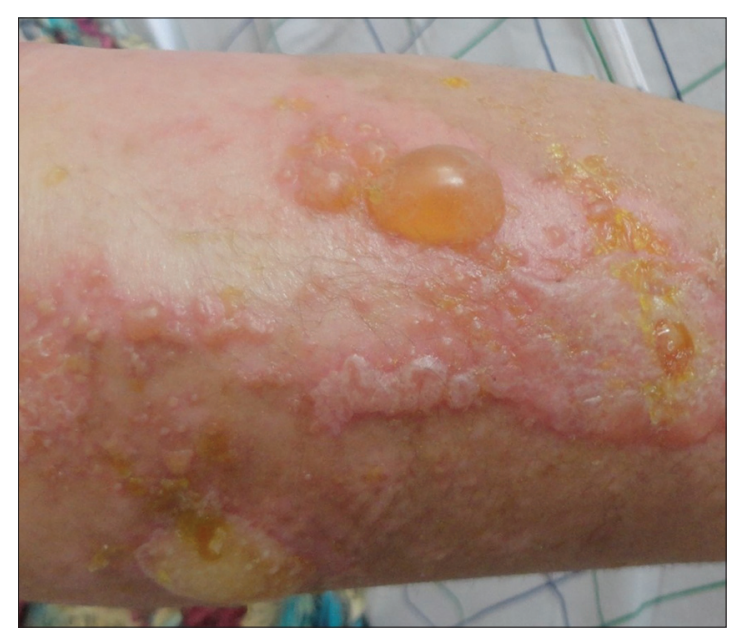

Figure 1: Image of the arm of the patient showing erythema and bullae on vitiligo patches.

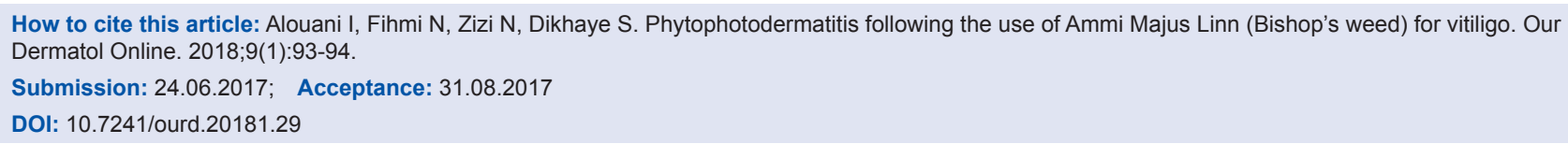


Nowadays, with the easy access to information, the anarchic recourse to herbal remedies can be dangerous for our patients. The use of phytotherapy should be cautious without scientific studies proving the efficiency and the safety of the plants use.

\section{REFERENCES}

1. Benhiba H, Hamada S, Ennouhi MA, HAssam B, Ihrai H. Phytodermatoses ou brûlures chimiques: attention aux plantes dangereuses. Ann Dermatol Venereol. 2011;138:131.

2. Ossenkoppele PM, Van der Suis WG. Phototoxicdermatitis following the use of Ammi majus fruit for Vitiligo. Ned Tijdschr Geneeskd. 1991;135:478-80.
3. Dollahite JW, Younger RL, Hoffman GO. Photosensitization in cattle and sheep caused by feeding Ammi majus. Am J Vet Res. 1978;39:193-7.

4. Kavli G, Volden G. Phytophotodermatitis. Photodermatol. 1984;1:65-75.

5. Kiistala R, Mäkinen-Kiljunen S, Heikkinen K, Rinne J, Haahtela T. Occupational allergic rhinitis and contact urticaria caused by bishop's weed (Ammi majus). Allergy. 1999;54:635-9.

6. Sidi E. Bourgeois-Gavardin J. The Treatment of Vitiligo with Ammi Majus Linn: A Preliminary Note. J of Invest Dermatol. 1952;5:391-5.

Copyright by Imane Alouani, et al. This is an open-access article distributed under the terms of the Creative Commons Attribution License, which permits unrestricted use, distribution, and reproduction in any medium, provided the original author and source are credited.

Source of Support: Nil, Conflict of Interest: None declared. 